\title{
METASSÍNTESE QUALITATIVA SOBRE OS ESTUDOS DE CRENÇAS, EMOÇÕES E IDENTIDADE (2009-2015)
}

\author{
Suellen Thomaz de Aquino Martins* \\ Núbia Enedina Santos Soura ${ }^{* *}$ \\ Rodrigo Camargo Aragão ${ }^{* * *}$
}

RESUMO: Buscamos neste artigo mapear estudos que considerem o papel das emoções e crenças no ensino-aprendizagem de Língua Estrangeira (LE) e como se dá a inter-relação desses fenômenos com a identidade do professor de LE. Apresentamos uma metassíntese qualitativa de estudos envolvendo estes conceitos, publicados no Brasil entre 2009 e 2015. A base de dados da SciELO foi utilizada como fonte na busca por periódicos com webqualis de relevância A1a B3 da área de Letras/Linguística. Os resultados indicam que a maioria dos estudos se debruçam sobre crenças e identidade de professor de línguas em formação inicial e continuada. Observarmos um leve pressionamento sobre as questões de crenças e emoções. Apontamos a necessidade de estudos que relacionem crenças-identidade-emoções no ensino-aprendizagem e formação do professor de LE, visto que, nesta metassíntese qualitativa, não foi encontrado nenhum trabalho que envolvesse os três conceitos como parte de um mesmo estudo.

PALAVRAS-CHAVE: Crenças; Emoção; Identidade.

\section{Introdução}

Pesquisas no campo da Linguística Aplicada vêm apontando o professor como foco de investigação e alterações de paradigmas sobre seu papel em sala de aula (CELANI, 2002; 2010; GIMENEZ, 2011). Estudos que investigam questões ligadas às crenças, identidades

\footnotetext{
* Mestre em Letras: Linguagens e Representações pela da Universidade Estadual de Santa Cruz (Uesc).

** Mestre em Letras: Linguagens e Representações pela da Universidade Estadual de Santa Cruz (Uesc).

*** Doutor em Linguística pela UFMG. Pós-doutor em Linguística Aplicada no POSLIN/UFMG. Professor dos Programas de Pós-graduação e Licenciatura em Letras da Universidade Estadual de Santa Cruz (Uesc).
} 
e/ou emoções têm crescido nessa área e trazido contribuições para a formação inicial e/ou continuada de professores. Assim, diante desse crescente, é nosso objetivo verificar como esses estudos estão aparecendo no cenário nacional, de modo imbricado entre si ou abordando-os de forma isolada. No entanto, salientamos que, de maneira mais focal, desejamos verificar se já há estudos, no cenário acadêmico brasileiro, que trabalham com os conceitos de crenças, identidades e emoções conjuntamente e de que modo acontece essa abordagem, pois temos a hipótese de que essa lacuna pode estar em aberto e tais conceitos estão aparecendo como basilares na literatura.

Estudos sobre a identidade do professor de línguas sugerem que os conhecimentos que os professores em formação trazem da universidade são importantes na construção da identidade desse profissional (TELLES, 2004; MALATER, 2008). Por sua vez, estudos que fazem uma interface entre crenças e emoções (MASTRELLA-ANDRADE, 2010; ARAGÃO, 2010, 2011; BARCELOS, 2011; COELHO; BARCELOS, 2010) sugerem influências destas no ensino/aprendizagem de língua estrangeira e na formação do professor e, por conseguinte, na construção da identidade deste profissional. Segundo Zembylas (2003) fatores como identidade, crenças e prática do professor estão relacionados com suas emoções. Desse modo, entender emoções de professores é crucial para se compreender a construção de sua identidade, suas crenças e a influências desses fenômenos sobre ensino e aprendizagem.

Essa área de estudo ganhou um maior interesse na literatura de formação de professores (JAMES-WILSON, 2001; ZEMBYLAS, 2003, 2004, 2005; RICHARDS, 2011). James-Wilson (2001) explora a relação entre a identidade pessoal e profissional através da explicação de como os professores se sentem sobre eles mesmos e sobre os alunos e como isso influencia no comportamento dos professores. Zembylas (2005) investiga a identidade dos professores bem como as emoções envolvidas no processo de ensino e como esses fenômenos participam do processo de tomadas de decisão e gerenciamento na sala de aula. Richards (2011) investiga o processo de ensino e aprendizagem em sala de aula, as crenças, conhecimentos, habilidades e formação de professor de línguas. 
$\mathrm{Na}$ última década no cenário brasileiro da LA, despontam estudos que começam a espelhar situações de confrontos emocionais, afetivos, relacionais, sociais e oferecem caminhos e alternativas para lidar com esses tipos de conflitos e, assim, evitar traumas, engessamento de perspectivas e até mesmo o abandono da profissão. Exemplos de trabalhos nessa perspectiva são os trabalhos de Aragão (2014), Rezende (2014) e Coelho (2014), que descrevemos, em síntese, nos parágrafos a seguir.

Aragão (2014) focaliza as experiências, crenças e emoções de um estudante do primeiro semestre do curso de Letras. Esse autor propõe que aspectos emocionais, históricos e sociais têm relevância juntamente com a cognição no processo de compreensão da aprendizagem. Rezende (2014) é uma professora de inglês da rede pública de ensino que investigou suas próprias emoções e buscou responder quais eram as suas emoções, como elas eram construídas e como essas se relacionavam com a sua prática.

Coelho (2014, p. 277) faz importantes referências aos fatores emocionais que refletem na atuação do professor, mas que tiveram sua gênese nas experiências da formação inicial e até mesmo, em experiências como aprendiz, antes da graduação. "Essas experiências se fundam em emoções, como tristeza e frustação que constituem um sistema de relações de trabalho prejudicial ao desenvolvimento profissional".

Esses trabalhos são exemplos de como o tema das emoções tem sido abordado. Além disso, o ano de publicação deles não são apenas coincidentes, mas são indicativos de que recentemente tem aumentado a preocupação com a temática sobre esse enfoque, e de alguma forma, o reconhecimento de sua importância. Todos estes estudos trazem contribuições para a pesquisa que engloba o ensino e a aprendizagem de línguas estrangeiras, no entanto, observa-se aí uma lacuna a ser preenchida acerca de estudos que abarquem a inter-relação entre crenças, emoções e identidade na formação do professor de línguas de modo imbricado. Alguns esforços neste sentido começam a aparecer em nosso cenário de produção científica como é o caso de Aragão (2010, 2011), Mastrella (2010) e Barcelos (2013). A compreensão acerca de possíveis inter-relações entre emoções e crenças fortalecem nosso entendimento, por exemplo, sobre como a vergonha, a ansiedade e a 
inibição limitam o ato de falar inglês em sala de aula (ARAGÃO, 2011; MASTRELLAANDRADE, 2011; MICCOLI, 2010). Aragão (2011) argumenta como as emoções influenciam o uso de língua estrangeira e se relacionam com crenças sobre nós mesmos, nossas identidades, nossos contextos de ensino/aprendizagem, e acerca de possíveis colegas-interlocutores.

Aragão (2010) explorou a inter-relação entre crenças, estilos cognitivos e emoções no ensino/aprendizagem de inglês e como a conscientização se repercute na trajetória de professores de línguas em formação inicial. Com o uso de procedimentos da pesquisa narrativa, seis estudantes refletiram sobre o papel de suas emoções e histórias de aprendizagem em sua conduta na sala de aula resultando em conscientização sobre suas crenças e emoções e a influência dessas na prática situada. A pesquisa reforçou o papel das experiências prévias na configuração de crenças, emoções e estilos cognitivos que se interagem em um sistema de relações no contexto da sala de aula. Alguns participantes, que viveram conflitos de crenças e estilos cognitivos, expressaram uma conduta que ofereceu resistência ao estilo de ensino do professor da disciplina. O trabalho investiga a maneira como os estudantes da pesquisa lidam com suas crenças, emoções e estilos cognitivos no contexto de sua aprendizagem.

Mastrella (2011) pesquisou as crenças que podem gerar e sustentar a ansiedade quando se refere à aprendizagem de língua estrangeira a partir de seis alunos de língua inglesa em um curso de extensão oferecido por uma instituição federal. Os resultados revelaram que os alunos ansiosos mostraram crenças negativas sobre si mesmos, se sentido incapazes para aprender a língua inglesa, sentindo-se, muitas vezes, envergonhados quando cometiam erros em sala de aula. A autora ressalta a importância de os professores considerarem a ansiedade como um dos motivos que ocasiona o baixo desempenho de estudantes, ao invés de considerarem somente a falta de habilidade ou de motivação.

Barcelos (2013), em um trabalho teórico, explora a relação complexa entre emoções, crenças e identidade. A pesquisadora argumenta que a compreensão dessa relação é importante por algumas razões. Primeiramente, a autora argumenta que a cognição tem 
relação direta com a emoção e vice-versa. Em segundo lugar, Barcelos (2013) sugere que o domínio emocional é um dos menos investigados na pesquisa de cognição de professores (BORG, 2006). Entretanto, a cognição de professores envolve não somente o que os professores pensam, sabem e acreditam, mas também como eles sentem sobre o ensino e aprendizagem de línguas. Emoções e ações estão associadas e é preciso aprofundar as pesquisas que compreendam a relação entre cognição e emoção de professores. E em terceiro lugar, a pesquisadora aponta que é relevante pesquisar o tema, porque nenhum estudo empírico até o momento pesquisou como identidades, emoções e crenças são interconectados explicitamente. A autora faz uma revisão de literatura sobre os três conceitos, a fim de mostrar a relação entre eles e ainda faz sugestões pesquisas que estão por vir e discute as implicações para estudos no contexto de ensino e aprendizagem.

Partindo da conclusão de Barcelos (2013) de que, no campo da Linguística Aplicada, os estudos que relacionam crenças, emoções e identidade dentro da área de formação de professor de línguas ainda são poucos, vemos a necessidade de fazer uma revisão sistemática dos estudos publicados em periódicos com webqualis de relevância A1 a B3, a fim de: a) recuperar estudos sobre os temas, publicados no período de 2009 a 2015; b) analisar os contextos, implicações e resultados de pesquisa de cada estudo recuperado, c) indicar demandas para futuros estudos no âmbito do ensino-aprendizagem e/ou formação de professores de línguas.

Isto permitirá que se tenhamos conhecimento sobre as pesquisas realizadas em nosso país, dando-lhes visibilidade e possibilitando vislumbrar uma interlocução entre os estudos que tratam de crenças e/ou emoções e /ou identidade, aparentemente de modo isolado ou em pares, mas que podem trazer em seu interior um pressionamento entre os termos. Para isso, primeiro, descrevemos a metodologia de pesquisa, em seguida, fazemos a metassíntese qualitativa (BORDINI e GIMENEZ, 2014) dos dados recuperados, discutindo os resultados da análise e finalizamos indicando o preenchimento de possíveis lacunas. 


\section{Caminhos metodológicos}

Um estudo sobre revisão sistêmica e metassíntese qualitativa

As conclusões de estudos publicados em periódicos de relevância nacional são um precioso meio que informam rumos, lacunas e tendências de pesquisa. Desse modo, a metassíntese qualitativa se mostra uma metodologia viável para este trabalho, uma vez que permite através da síntese de estudos primários, valorizá-los e situá-los em um panorama mais amplo e abrangente, por meio de uma abordagem agregativa e interpretativa.

Várias denominações têm sido adotadas para designar esta metodologia: meta-estudo, meta-etnografia, grounded formal theory, meta-análise qualitativa, meta-interpretação, meta-síntese qualitativa, síntese crítico-interpretativa, sendo a mais comum, meta-síntese (SANDLOWSKI e BARROSO, 2003). Aliamos neste estudo a metasssíntese qualitativa (por todo o exposto) com a revisão sistêmica, sendo esta última utilizada como método para busca dos textos. Assim, primeiro procedemos a revisão sistêmica e após a recuperação dos textos, fizemos a análise por meio da metassíntese qualitativa.

A escolha pela revisão sistemática se deu por conta da "possibilidade de sintetizar informações relevantes pautadas [...] em estratégias de busca de informações relacionadas a um assunto de interesse (SARNIGHAUSEN, 2011, p. 30). E ela precede a metassíntese pois "apresenta metodologia de separação de informações relevantes, apoiada em critérios bem definidos e protocolo de atuação, indicando sites de busca, palavras chave utilizadas [...] entre outros fatores" (SARNIGHAUSEN, 2011, p. 31).

Esse protocolo de ações da revisão sistemática permite uma orientação para o trabalho inicial, que começa segundo Sarnighausen (2011) com dois passos, a saber: delimitação do universo de investigação - delimita a área de investigação através de parâmetros, e os processos de leitura para o reconhecimento - classificação de qualidade dos textos. O resultado desta primeira etapa é a seleção de textos que obedecem aos critérios iniciais de inclusão definidos pelos interesses da pesquisa. 
Com este conjunto de textos definidos, passa-se a análise dos mesmos, usando-se da metassíntese qualitativa. Para esta análise é feita uma "descrição informativa dos estudos para localização no tempo, na sociedade e comunidade científica, identificação da obra [...] e caracterização da obra" (SARNIGHAUSEN, 2011, p. 49) e uma narrativa que busca relacionar aspectos dos textos com o objetivo da pesquisa, "associação de ideias, comparações, destaque para considerações relevantes e conclusivas" (SARNIGHAUSEN, 2011, p. 49).

É importante salientar que este tipo de pesquisa é muito comum nas ciências médicas e agrárias, como é o caso da pesquisa de Sarnighausen (2011) que se situa na área de ciências agrárias mas que serviu de base para Bordini e Gimenez (2014) em seu estudo sobre inglês como Língua Franca, no campo da Linguística Aplicada. Por isto, escolher Bordini e Gimenez (2014) como referência no desenvolvimento de nossa pesquisa foi mais viável. Essas autoras usaram essa metodologia em seu estudo e assim acreditamos que não se faz necessário uma nova adaptação de metodologia das ciências agrárias para o campo da Linguística Aplicada.

\section{SciELO - O porquê desta base de dados?}

A rede $\mathrm{SciELO}^{1}$ existe há quinze anos e nasceu como estratégia para alavancar a presença muito tímida de periódicos de países em desenvolvimento nos índices internacionais. Surgiu no Brasil em uma parceria entre a FAPESB e o Centro Latino-Americano e de Caribe de informação em Ciências da Saúde (BIREME/OPAS/OMS). Após um ano de projeto piloto envolvendo dez periódicos indexados no Science Citation Index (SCI), resultou em um modelo de indexação e publicação começando a ser adotados por outros países, abarcando hoje, 14 países e um ainda em desenvolvimento.

${ }^{1}$ Scientific Eletronic Library on line; http://www.scielo.org/php/index.php 
A SciELO teve em sua gênese dois propósitos (PACKER, 2014, p.15): “a indexação de periódicos nacionais de qualidade para complementar os índices internacionais e a publicação de textos completos de acesso aberto, na Internet, na modalidade conhecida atualmente como "Via Dourada" (Golden Road)" e "a convergência cooperativa de editoras independentes, editores e agências nacionais de pesquisa acerca do objetivo comum de aumentar a qualidade e visibilidade dos periódicos".

No decorrer destes 15 anos a SciELO tornou-se referência por conta do padrão de qualidade dos periódicos que indexava. Prova disso são os números que não permitem dúvidas, a saber: "a rede publicou até hoje um total de mais de 400 mil artigos de acesso aberto, verificando-se uma média diária de mais de 1,5 milhões downloads de artigos, sendo 65\% deles em PDF e 35\% em HTML” (PACKER, 2014, p. 16). Em julho de 2013, o Ranking Web of Repositoires publicou que a SciELO Brasil ficou em primeiro lugar em número de acessos no top portals.

Além do mais, a SciELO é usada em muitos dos países que participam da rede, inclusive o Brasil, como referência em avaliações de pesquisa e também nas avaliações realizadas com base nos índices internacionais (PACKER, 2014). Diante do exposto, entendemos que a credibilidade e confiabilidade dos dados obtidos nesta fonte de pesquisa não permite dúvidas acerca da importância da mesma e ainda nos permite uma otimização do fator temporal, uma vez que reúne em seu banco de dados, indexações e publicações qualificadas.

\section{Design de pesquisa}

Este trabalho abarca um levantamento de estudos publicados em periódicos nacionais com webqualis de relevância A1 a B3. A escolha pela recuperação apenas de estudos publicados em periódicos se justifica pelo fato de que em periódicos a informação é veiculada de modo mais rápido; acesso a diversos estudos em uma mesma edição; e ainda considerando que textos congruentes a teses e dissertações tendem a ser publicados em perió- 
dicos. O recorte da relevância do webqualis de A1 a B3 teve como propósito englobar pesquisas feitas por alunos e professores, mestrandos, doutorandos, mestres e doutores no contexto de produção científica.

Fizemos a recuperação de estudos de 2009 a 2015, cujos temas envolvessem emoções e/ou crenças e/ou identidade do professor de Línguas Estrangeiras no contexto de sua formação, seja ela inicial ou continuada. O levantamento dos estudos foi realizado de abril a maio de 2015 e atualizado em agosto do mesmo ano. Como estratégias de busca na fonte pesquisada, foram utilizados os termos: "emoções”; “crenças"; "identidade”; “emoções e crenças"; "emoções e identidade"; "crenças e identidade"; "emoções, crenças e identidade" como palavras-chave em todos os índices.

Embora buscamos a tríade emoções-crenças-identidades, o próprio design da metassíntese pela SciELO pode deixar escapar artigos que possam abordar tais temas, mas não os indicaram nem no título e/ou nas palavras-chave. Ainda, ciente que o contexto era formação, inicial ou continuada, de professores de línguas estrangeiras, decidimos não colocar o contexto como palavra-chave a fim de evitar que houvesse restrições de resultados. Seguimos como base para pesquisa o protocolo de ações de Sarnighausen (2011 apud BORDINI e GIMENEZ, 2014), a saber:

- Parâmetro temático: crenças; emoções; identidades; formação inicial e/ou continuada do professor de línguas estrangeiras em pré-serviço ou em serviço;

- Critérios de inclusão: as temáticas, juntas ou separadas, estarem diretamente ligadas ao contexto de formação, inicial e/ou continuada, de professor de línguas estrangeiras. Os textos que em seu título, resumo e palavras-chave não se relacionassem ao contexto de formação, foram excluídos. Foram selecionados os filtros: método - integrada; onde: Brasil; ano de publicação - 2009 a 2015; SciELO áreas temáticas - Linguistics, Letters and Arts;

- Parâmetros linguísticos: Português ou inglês;

- Fontes bibliográficas: site SciELO;

- Parâmetro cronológico: 2009 a 2015 
Foram realizadas duas leituras para a recuperação dos trabalhos selecionados para a pesquisa:

- Leitura de cunho exploratório, de forma rápida e direta, identificando textos relevantes a partir dos títulos, resumos e palavras-chave, etc. Foram priorizados os textos cujas temáticas relacionassem as palavras Crenças, Emoções, Afetividade, Experiências de professores de Línguas, Identidade de professor de Línguas Estrangeiras com o contexto de formação, inicial/pré-serviço ou continuada/em serviço.

- Leitura de cunho seletivo, de forma integral, demarcando os textos que realmente seriam selecionados e que iam de encontro ao escopo da pesquisa.

Quadro 1 - Total de trabalhos selecionados

\begin{tabular}{|c|c|c|c|}
\hline $\begin{array}{l}\text { Ferramenta } \\
\text { de busca }\end{array}$ & Procedimentos & $\begin{array}{l}\text { Trabalhos } \\
\text { encontrados }\end{array}$ & $\begin{array}{c}\text { Trabalhos } \\
\text { selecionados }\end{array}$ \\
\hline \multirow{3}{*}{ Scielo } & $\begin{array}{l}\text { - O termo, emoções, foi } \\
\text { colocado entre (“") a } \\
\text { fim de restringir a temá- } \\
\text { tica } \\
\text { - A seleção foi feita a par- } \\
\text { tir da leitura do título e } \\
\text { do resumo priorizando } \\
\text { aqueles que estavam rela- } \\
\text { cionados com a emo- } \\
\text { ções de professores de } \\
\text { LE }\end{array}$ & 11 & 0 \\
\hline & $\begin{array}{l}\text { - O termo, crenças, foi } \\
\text { colocado entre (“") a } \\
\text { fim de restringir a temá- } \\
\text { tica } \\
\text { - A seleção foi feita a par- } \\
\text { tir da leitura do título e } \\
\text { do resumo priorizando } \\
\text { aqueles que estavam rela- } \\
\text { cionados com crenças } \\
\text { na formação de profes- } \\
\text { sores de LE }\end{array}$ & 18 & 1 \\
\hline & $\begin{array}{l}\text { - O termo, crenças, foi } \\
\text { colocado entre (" ") a } \\
\text { fim de restringir a temá- } \\
\text { tica } \\
\text { - A seleção foi feita a par- } \\
\text { tir da leitura do título e }\end{array}$ & 18 & 2 \\
\hline
\end{tabular}




\begin{tabular}{|c|c|c|c|}
\hline \multirow{6}{*}{ Scielo } & $\begin{array}{l}\text { do resumo priorizando } \\
\text { aqueles que estavam rela- } \\
\text { cionados com crenças } \\
\text { de professores de LE } \\
\text { em serviço }\end{array}$ & & \\
\hline & $\begin{array}{l}\text { - O termo, crenças, foi } \\
\text { colocado entre (“") a } \\
\text { fim de restringir a temá- } \\
\text { tica } \\
\text { - Nos resultados pude- } \\
\text { mos selecionar um texto, } \\
\text { a partir da leitura do tí- } \\
\text { tulo e do resumo, que es- } \\
\text { tava relacionado com } \\
\text { crenças e emoção de } \\
\text { professor de LE em } \\
\text { serviço }\end{array}$ & 18 & 1 \\
\hline & $\begin{array}{l}\text { - O termo, identidade, foi } \\
\text { colocado entre (“") a fim } \\
\text { de restringir a temática } \\
\text { - A seleção foi feita a par- } \\
\text { tir da leitura do título e } \\
\text { do resumo priorizando } \\
\text { aqueles que estavam rela- } \\
\text { cionados com (re) cons- } \\
\text { trução da identidade } \\
\text { do professor de LE em } \\
\text { formação }\end{array}$ & 77 & 3 \\
\hline & $\begin{array}{l}\text { - O termo, identidade, foi } \\
\text { colocado entre ("”) a fim } \\
\text { de restringir a temática } \\
\text { - A seleção foi feita a par- } \\
\text { tir da leitura do título e } \\
\text { do resumo priorizando } \\
\text { aqueles que estavam rela- } \\
\text { cionados com constru- } \\
\text { ção da identidade do } \\
\text { professor de LE em } \\
\text { serviço }\end{array}$ & & 1 \\
\hline & $\begin{array}{l}\text { - O termo, identidade, foi } \\
\text { colocado entre (“") a fim } \\
\text { de restringir a temática } \\
\text { - A seleção foi feita a par- } \\
\text { tir da leitura do título e } \\
\text { do resumo priorizando } \\
\text { aqueles que estavam rela- } \\
\text { cionados com emoções } \\
\text { e crenças }\end{array}$ & 0 & 0 \\
\hline & $\begin{array}{l}\text { - O termo, identidade, foi } \\
\text { colocado entre (" ") a fim } \\
\text { de restringir a temática } \\
\text { - A seleção foi feita a par- } \\
\text { tir da leitura do título e }\end{array}$ & 0 & $V$ \\
\hline
\end{tabular}




\begin{tabular}{|c|c|c|c|}
\hline & $\begin{array}{l}\text { do resumo priorizando } \\
\text { aqueles que estavam rela- } \\
\text { cionados com emoções } \\
\text { e identidade }\end{array}$ & & \\
\hline & $\begin{array}{l}\text { - O termo, identidade, foi } \\
\text { colocado entre ("”) a fim } \\
\text { de restringir a temática } \\
\text { - A seleção foi feita a par- } \\
\text { tir da leitura do título e } \\
\text { do resumo priorizando } \\
\text { aqueles que estavam rela- } \\
\text { cionados com identi- } \\
\text { dade e crenças }\end{array}$ & 0 & 0 \\
\hline Scielo & $\begin{array}{l}\text { - O termo, identidade, foi } \\
\text { colocado entre (" ") a fim } \\
\text { de restringir a temática } \\
\text { - A seleção foi feita a par- } \\
\text { tir da leitura do título e } \\
\text { do resumo priorizando } \\
\text { aqueles que estavam rela- } \\
\text { cionados com emoções, } \\
\text { identidade e crenças }\end{array}$ & 0 & 0 \\
\hline
\end{tabular}

II. Estudos sobre emoções, crenças, identidade do professor de LE - Pesquisas realizadas no Brasil - Onde caminham os artigos

No quadro 2 a seguir, apresentamos as características gerais dos trabalhos encontrados na presente investigação, com o tema de pesquisa, a evolução das produções, o ano de publicação e seus respectivos autores.

Quadro 2-Características gerais dos trabalhos

\begin{tabular}{|l|l|c|l|}
\hline \multicolumn{1}{|c|}{ Tema } & \multicolumn{1}{|c|}{ Apresentação } & $\begin{array}{c}\text { Evolução } \\
\text { das pesquisas }\end{array}$ & Autores \\
\hline $\begin{array}{l}\text { Crenças de pro- } \\
\text { fessor de LE em } \\
\text { formação conti- } \\
\text { nuada }\end{array}$ & $\begin{array}{l}\text { O uso de instrumentos e procedi- } \\
\text { mentos de pesquisa sobre crenças: } \\
\text { promovendo formação reflexiva; } \\
\text { crenças sobre o ensino e aprendiza- } \\
\text { gem de espanhol em uma escola pú- } \\
\text { blica; }\end{array}$ & 2010; 2013 & MOREIRA E \\
MONTEIRO; VESZ
\end{tabular}




\begin{tabular}{|l|l|l|l|}
\hline $\begin{array}{l}\text { Crenças de pro- } \\
\text { fessor de LE em } \\
\text { formação }\end{array}$ & $\begin{array}{l}\text { Interação de crenças em contexto } \\
\text { colaborativo virtual de aprendiza- } \\
\text { gem de línguas }\end{array}$ & 2013 & $\begin{array}{l}\text { BEDRAN E SALO- } \\
\text { MÃO }\end{array}$ \\
\hline $\begin{array}{l}\text { Crenças e Emo- } \\
\text { ção de professor } \\
\text { de LE em serviço }\end{array}$ & $\begin{array}{l}\text { A correção em língua estrangeira a } \\
\text { partir de uma perspectiva sociocul- } \\
\text { tural e as crenças de professores so- } \\
\text { bre o assunto }\end{array}$ & 2015 & $\begin{array}{l}\text { BATTISTELLA E } \\
\text { LIMA }\end{array}$ \\
\hline $\begin{array}{l}\text { Identidade do } \\
\text { professor de LE } \\
\text { em forma- } \\
\text { ção/pré-serviço }\end{array}$ & $\begin{array}{l}\text { O processo identificatório na prá- } \\
\text { tica de assistência ao aluno com di- } \\
\text { ficuldades de inglês como LE no } \\
\text { curso de Letras; Comunicação } \\
\text { transnacional mediada por compu- } \\
\text { tador: uma análise discursiva das } \\
\text { identidades de futuros professores } \\
\text { de inglês no Facebook; Formação } \\
\text { de professores em inglês préser- } \\
\text { viço em Alagoas: uma reflexão so- } \\
\text { bre identidades; }\end{array}$ & 2009;2014 (2) & $\begin{array}{l}\text { LARDO; GTELLA E } \\
\text { CRUZ }\end{array}$ \\
\hline $\begin{array}{l}\text { Identidade do } \\
\text { professor de LE } \\
\text { em formação } \\
\text { continuada }\end{array}$ & $\begin{array}{l}\text { Teorizando a prática ou praticando } \\
\text { a teoria? Os deslocamentos identi- } \\
\text { tários de duas professoras de inglês } \\
\text { em um grupo de pesquisa-ação }\end{array}$ & 2011 & $\begin{array}{l}\text { REIS, SILVA E } \\
\text { TORRES }\end{array}$ \\
\hline
\end{tabular}

Do total de 8 trabalhos analisados, todos se configuram como pesquisas empíricas, ou seja, voltados para as experiências do pesquisador e/ou participantes, não sendo nenhum ensaístico, com foco somente na reflexão dos autores. Os estudos, em sua maioria, utilizam como metodologia as narrativas/relatos dos participantes como instrumento de coleta de dados. Apesar de contextos de pesquisas variados, os trabalhos buscavam compreender questões ou de identidade, ou de emoção e ou de crenças do professor de LE em formação inicial ou continuada.

Como se pode observar, ainda são incipientes as pesquisas no Brasil que abordam os temas emoções, identidade e crenças de professor, quer seja na sua formação (inicial/continuada) de forma imbricada. Dos 8 trabalhos encontrados, no que tange às crenças de professor foram encontrados no total 4 trabalhos. Destes, somente 1 é voltado às crenças de professor em formação inicial e 3 são voltados às crenças de professor em formação continuada, sendo um deles traz o pressionamento entre crenças e emoções do professor. 
Os outros 4 trabalhos discutem sobre a questão de identidade do professor, sendo que 3 tratam desta questão na formação inicial e 1 na formação continuada.

No que tange às crenças, de acordo com Borg (2006), o estudo de crenças foi iniciado nos anos 70 com a publicação dos trabalhos de Clark e Peterson (1986), Shavelton e Stern (1981) e Shulman (1986) sobre o pensamento e conhecimento dos professores. Algumas primeiras investigações tinham também como objetivo a identificação das crenças (HORWITZ, 1985; CARVALHO, 2000). Na presente pesquisa, em relação às crenças de professor em serviço, Moreira e Monteiro (2010) investigam quais os tipos de crenças que podem ser detectados a partir da utilização de diferentes instrumentos e procedimentos, a fim de saber se esses instrumentos afetam na forma como os professores refletem sobre as suas crenças e quais combinações desses instrumentos e procedimentos são eficientes para a realização da reflexão.

Nessa pesquisa de natureza etnográfica foram utilizados cinco instrumentos e procedimentos de pesquisa, a saber: questionário, grupo focal, auto-relato, observação de aulas e entrevistas (com uso do stimulated recall); com cinco professoras de inglês de uma escola de línguas de uma cidade do interior de São Paulo. Os resultados apontaram que a partir dos instrumentos e procedimentos de pesquisa investigados as crenças puderam ser levantadas; sugerindo, no entanto, a combinação desses instrumentos e procedimentos a fim de encontrar o caminho interessante para a realização do processo reflexivo.

Por sua vez, Zolin-Vesz (2013) a partir de relatos da professora de espanhol, da coordenadora pedagógica e da diretora de uma escola busca entender duas crenças relacionadas à adoção do ensino de língua espanhola na escola, ofertada como disciplina compulsória e única de LE para alunos do $6^{\circ}$ ao $9^{\circ}$ ano desde o ano 2000. Nesta pesquisa, o autor entende crenças a partir do conceito de Barcelos e Kajala (2011) ao afirmar que elas são produtos sociais, históricos e políticos conectados aos contextos sociopolíticos mais amplos. Os resultados dessa pesquisa mostram que a escola onde aconteceu a pesquisa "parece constituir um lugar de manutenção e reprodução do status quo”, simbolizando, por outro lado, "também um lugar de sonhos, de desejos e anseios por uma vida melhor e 
uma sociedade menos estratificada" (ZOLIN-VESZ, 2013, p. 826). Ainda, indicam que existem papéis outros também atribuídos ao ensino e aprendizagem da língua espanhola que não são somente "encarta[r] sua aspiração como elemento de integração regional, conforme expressam os documentos que regulam o ensino no Brasil" (ibidem), sugerindo assim que mais pesquisas e questionamentos sejam feitos a respeito, a fim de se refletir sobre a função conferida, historicamente pela sociedade, ao ensino e à aprendizagem do espanhol.

Destaca-se o trabalho de Battistella e Lima (2015) que a partir de uma perspectiva sociocultural (VYGOTSKY, 1986) discutem sobre o feedback corretivo na sala de aula de língua estrangeira, considerando alguns aspectos afetivos no processo de correção. Este tipo de feedback pode ser entendido como uma reação do professor, que transforma, sinaliza desaprovação ou pede uma melhora na fala do aprendiz podendo ter relação com fatores afetivos e às crenças dos professores. Batistela e Lima (2015) procuram pesquisar o processo de correção no ensino/aprendizagem de língua estrangeira a partir de relatos de quatro professores à luz da perspectiva sociocultural de Vygotsky (1986). As crenças dos professores sobre a correção foram evidenciadas na pesquisa e os dados sugerem relações entre as crenças e alguns fatores afetivos envolvidos no processo de correção em sala de aula. Os resultados apontam para uma atitude positiva por parte dos professores sobre a correção, considerando-a como elemento que auxilia o processo de aprendizagem. Entretanto, limitações na metodologia, que se circunscreveu a análise de relatos, se afasta de uma perspectiva situada de pesquisa em crenças (BARCELOS, 2004, 2006) devido à ausência de dados do contexto de sala de aula, que poderia mostrar a relação entre as crenças e as ações em sala de aula.

Embora fatores afetivos sejam considerados no trabalho, estes não estão articulados de uma maneira inter-relacionada na estrutura teórica, bem como evidenciados na análise dos dados. Isso pode ser explicado pela epistemologia de base marxista-dialética da teoria sociocultural. A teoria sociocultural de Vygotsky (1986) tende a privilegiar o papel da prá- 
tica social em sua epistemologia, limitando a reciprocidade fisiologia/interações e emoção/cognição e as relações que ocorrem entre emoção, ação e crenças em dinâmicas relacionais que através de teorias com base na corporeidade e perspectivas sistêmicas podem ser aprofundadas (ARAGÃO, 2005).

Por outro lado, nota-se na discussão dos dados uma interface entre crenças sobre o processo de correção e aspectos afetivos como a vergonha, constrangimento e demanda por confiança nos processos de correção. Nesta esteira, Batistela e Lima (2015, p. 293) corroboram pesquisa de Vicente e Ramalho (2009) que indicaram como os alunos ficam constrangidos ao falar de seus erros e que quanto mais cedo uma crença é incorporada ao sistema de crenças do indivíduo, é mais difícil alterá-la e, consequentemente, crenças recém-adquiridas são mais vulneráveis a mudanças. Não há discussão no artigo a respeito da questão sobre mudanças de crenças como iniciado por Barcelos (2007) que vai além da questão temporal na consolidação de uma crença de mais difícil mudança. Aragão (2011) mostra como as crenças centrais, que são relacionadas às emoções e identidades, ou seja, aos aspectos mais íntimos de nós mesmos, são mais difíceis de sofrerem mudanças. Os professores participantes de Batistela e Lima (2015, p. 298) acreditam que a correção direta, e feita a todo o momento, pode deixar o aluno constrangido. Isso acontece, de acordo com os professores participantes da pesquisa, por insegurança, ansiedade, timidez, baixa autoestima, medo de errar na frente dos colegas.

Ainda sobre a relação entre crenças e os aspectos afetivos, Batistela e Lima (2015, p. 297) nos mostram como os quatro professores unanimemente creem que há a necessidade de estabelecer um processo de confiança com os estudantes para que entendam os elementos envolvidos no processo corretivo, tomando consciência das crenças envolvidas aí e para que fiquem à vontade nas aulas, particularmente na produção oral, possivelmente por sentimentos associados ao medo de exposição em sala de aula. Neste sentido, embora não esteja explícito a relação entre crenças e emoções na estrutura teórica, as autoras afir- 
mam ser indispensável evidenciar a importância de se relacionar os preceitos da teoria sociocultural aos processos de correção e às emoções e às crenças dos professores (BATISTELA e LIMA, 2015, p. 299).

Embora as autoras tratem do tema: crenças e afetividade no âmbito da correção na aprendizagem de língua estrangeira, o artigo não o faz de maneira inter-relacionada e articulada em sua epistemologia. Outrossim, não há consideração explícita sobre os aspectos identitários. Observa-se que os conceitos são tratados de maneira separada, mesmo embora haja um pressionamento entre crenças e aspectos afetivos na discussão dos dados. Ainda, pesa uma reflexão conceitual feita em torno do tratamento dos fatores afetivos enquanto condições psicológicas individualizadas, como traços intrínsecos à personalidade dos estudantes. Nessa linha, as emoções tendem a ser entendidas como características individuais descontextualizadas. Nesta estrutura conceitual há uma tendência de perdermos o foco das inter-relações e das dinâmicas relacionais que se estabelecem e se intercruzam na sala de aula de língua estrangeira (ARAGÃO, 2010; MICCOLI, 2010; MASTRELA-ANDRADE, 2010; NORTON, 2013). Ao usarmos o termo "fator afetivo" tende-se a perder a visão voltada para as dinâmicas sistêmicas e imbricadas que ocorrem entre elementos diversos que compõem um sistema dinâmico, e falamos como se tudo ocorresse em um corpo/mente individual, ou mesmo somente para o ambiente e/ou para a atmosfera da sala de aula.

Sobre crenças de professor em formação inicial/pré-serviço, Bedran e Salomão (2013) investigaram as crenças em situações colaborativas de ensinar e aprender línguas, mais especificamente, acerca da interação das crenças entendidas através do discurso e das atitudes de duas alunas universitárias, de diferentes nacionalidades, aprendizes de italiano e português, a partir de uma parceria de Teletandem. O Teletandem é um instrumento tecnológica ligado à comunicação em tempo real com uso de vídeo e voz possibilita a interação oral com falantes da língua alvo em contextos de ensino e aprendizagem a distância (TELLES; VASSALO, 2006; TELLES, 2006) e busca permitir com que falantes de diferentes línguas trabalhem de forma colaborativa. Essa investigação vai de encontro com os estudos 
na área de ensino e aprendizagem de línguas que mostram um novo ponto de vista de ensino voltado não mais na figura do professor, mas sim na do aluno; e ainda com as bases do ensino colaborativo, fundamentados na interação e negociação de significados (CRANDALL, 2000). Seus resultados mostram o Teletandem tanto como uma experiência autônoma de aprendizagem quanto colaborativa (SOUZA, 2006) revelando que neste contexto as crenças aparentam ser mais explícitas do que em sala de aula devido ao número limitado de participantes.

Ainda, os resultados indicam a importância do trabalho com crenças, a fim de despertar os envolvidos para a conscientização sobre o ensino e aprendizagem de línguas e ainda a relevância sobre uma melhor preparação por parte dos professores-mediadores, a partir de um approach reflexivo. Consequentemente, segundo a autora, os participantes "poderão aprender a lidar com crenças diferentes das suas, de maneira que o Teletandem se torne um campo no qual conflitos de crenças não prejudiquem ou comprometam a aprendizagem e a formação desses futuros professores de línguas, mas sim gerem interação positiva e ressignificação das mesmas” (BEDRAN e SALOMÃO, 2013, p. 811).

No que diz respeito à identidade, é sabido, inicialmente, que a sua formação é um processo complexo. Envolve, como professores em formação e em serviço, construir o conhecimento pessoal e profissional, desenvolver o senso de ser professor e negociar paradigmas culturais e contextuais que modelam o significado do ensinar. Há outros estudos, no entanto, que indicam que a decisão profissional para as licenciaturas é algo que ocorre ao longo do curso de formação em consonância com outras experiências de ensino na prática (BENSON; NUNAN, 2004; PAIVA, 2007).

Nesta pesquisa, no que diz respeito à identidade de professor em formação/préserviço, Neves (2009) averigua, a partir dos estudos discursivos da psicanálise, os momentos de identificação dos alunos em formação para professor na modalidade de monitoria em uma universidade pública de Minas Gerais. Segundo a autora, "o programa de monitoria visa a possibilitar a prática da língua inglesa $(\mathrm{LI})$ para alunos com dificuldades em acompanhar essa habilitação” (NEVES, 2009, p. 564). Em sua investigação a autora analisa as 
respostas a entrevistas, depoimentos e notas de campo desses futuros professores a partir das aulas dadas, preparadas para alunos das disciplinas básicas necessárias à Habilitação em Inglês. Assim, Neves (2009) elucida as representações em relação não somente ao bom professor e ao bom aluno, mas também à forma como é visto o erro e à noção de língua. Por fim, a autora indica que o ensino e aprendizagem acontece através da identificação e, ainda, aponta para a importância da problematização sobre o processo de formação do futuro professor em relação à aprendizagem.

Por sua vez, Gallardo (2014) investigou as representações da identidade nacional constituídas em um contexto virtual, mais especificamente, a partir do contato em língua inglesa por duas estudantes de letras com estrangeiros pelo facebook. A autora focou em conversas informais mediadas por computador a fim de investigar nos discursos "a construção de identidades apresentadas a amigos virtuais cujos participantes tiveram pouco ou nenhum contato presencial" (GALLARDO, 2014, p. 555). Para isso, Gallardo fez uso da Análise Crítica do Discurso para mostrar a organização linguística e ideológica dos discursos nacionais incorporados na passagem para o contexto virtual/online.

Os resultados revelaram que uma das participantes, cujo pseudônimo é Bruna, descobriu a comunicação transnacional online como um lugar para reflexão e um espaço alheio a julgamentos de outros sujeitos. Ainda, o seu discurso ideológico denotou uma visão inferior sobre o Brasil em relação aos EUA e, consequentemente, sobre sua identidade. A segunda participante, de codinome Nara, teve sua identidade nacional destacada na comunicação transnacional não posicionando o Brasil de maneira inferior a outros países e valorizando-o. Por fim, a pesquisa aponta a importância da "hibridação de estratégias do discurso de contextos offline com os recursos multimodais dos contextos online. Os sujeitos adotaram estereótipos oriundos de centros geradores das dinâmicas de globalização, tanto em escala regional (sudeste do Brasil) como mundial (os EUA)" (GALLARDO, 2014, p. $553)$.

Por fim, Stella e Cruz (2014), a partir de narrativas pessoais (WEBSTER; MERTOVA, 2007), refletem sobre a formação de professores de língua inglesa em pré-serviço, 
portanto, na situação de graduandos do curso de Licenciatura em Letras em Alagoas. Para isso, tomam como base os conceitos de identidade e alteridade (PONZIO, 2010) por entenderem que a identidade desse professor é afetada pelo contexto vivido, fato esse que interfere em suas práticas na sala de aula. Os resultados revelam sobre a "impossibilidade da garantia de que nossa proposta formativa concretamente traga resultados para o contexto educativo do estado a curto e médio prazos" (STELLA; SILVA, 2014, p. 157). Sendo assim, os autores esperam que os graduandos em situação pré-serviço não percam de vista os valores positivos da educação e consequentemente não sucumbam às pressões contextuais, como também reafirmem sua "crença no sujeito freireano como agente transformador e na ação política como prática formativa, na interação como produtora de sentidos e na fluidez dos contextos por onde circulam esses sujeitos” (STELLA; SILVA, 2014, p. 157).

Em relação à identidade do professor de LE em serviço Reis, Silva e Torre (2011) investigam sobre o processo identitário de duas professoras de inglês da rede pública em Minas Gerais, através dos diários escritos por elas durante todo o ano em que a pesquisaação foi desenvolvida. A investigação foi realizada a partir de representações das participantes sobre o significado de ser professora, e ainda sobre suas expectativas sobre estar em um curso de formação continuada.

As autoras tomaram como base os conceitos da análise discursiva através da utilização das Ressonâncias Discursivas (SERRANIINFANTI, 2001) e tinham como objetivo descobrir como a pesquisa-ação abarca teoria e prática, na medida em que impulsiona as professoras a se (re) desvendarem de forma responsável em suas ações. Os resultados revelaram que "qualquer mudança na prática pedagógica será possível apenas ao entrelaçar teoria e prática, ao modo como o sujeito professor assume sua posição subjetiva e, a partir dela, constitui seu fazer, seu dizer e ser" (REIS; SILVA; TORRES, 2011, p. 71). Ou seja, durante a investigação, houve um revezamento entre as práticas anteriores com as novas, não havendo, no entanto, a completa troca de um pelo outro, como já defendia Hon (2009). Ainda, a voz do professor foi ouvida havendo assim uma reflexão sobre suas angústias e 
desafios, promovendo então o deslocamento identitário confrontados na proposta de pesquisa de sua própria ação (REIS; SILVA; TORRES, 2011).

Em suma, baseada na presente pesquisa, visto que nenhum trabalho foi encontrado abarcando emoções, identidade e crenças de professores de LE de forma imbricada, é importante salientar que apesar do leve pressionamento que aparece no trabalho de Battistella e Lima (2015) acreditamos que seja necessário que mais investigações versem sobre esses três aspectos de forma relacionada, pois acreditamos que a partir deles podemos desenvolver um entendimento mais aprofundado da interdependência entre crenças-identidadeemoções em questões vinculadas ao ensino/aprendizagem e à formação de professores de línguas estrangeiras.

\section{Considerações Finais}

O objetivo deste artigo foi mapear as publicações no Brasil sobre emoções, crenças e identidade no ensino-aprendizagem de línguas através de uma metassíntese qualitativa no período 2009-2015, tendo como fonte a base de dados da SciELO. A partir dos resultados analisados podemos afirmar que as investigações se apresentam como trabalhos voltados para as experiências do pesquisador e/ou dos participantes. Os contextos de pesquisas eram diversos, no entanto, em sua maioria, as considerações tinham como metodologia as narrativas dos participantes como instrumento de coleta de dados.

Destacamos, porém, que os trabalhos que investigam as emoções do professor de línguas são escassos e a única pesquisa encontrada - Battistella e Lima (2015) - que traz em seu bojo um pressionamento entre crenças e emoções, ainda se mostra embasada na perspectiva das variáveis afetivas, e aborda as emoções de maneira secundária e descontextualizada. Assim, observamos lacunas nos estudos revisados que apontem inter-relações entre contextos, pessoas, e o que emerge como elementos que disparam determinadas emoções, crenças, posicionamentos identitários e seus efeitos nas ações. Neste sentido, é importante salientar a necessidade de mais estudos que abordem emoções, pois acreditamos que emoções, crenças e identidades são fatores que impactam o processo de ensino/aprendizagem 
e de formação de professores de língua estrangeira (ARAGÃO, 2010; CELANI, 2010; COELHO, 2011; BARCELOS, 2013). A medida que o estudante ou o professor de línguas começar a compreender como as emoções e as crenças atuam na constituição de suas identidades e como essas influenciam o processo de ensino/aprendizagem, pode se tornar possível um trabalho a fim de agir por mudanças que busquem o fortalecimento do processo, caso isso seja conscientemente desejado (ARAGÃO, 2011).

$\mathrm{Na}$ pesquisa realizada na base de dados SciELO, dentro dos parâmetros de pesquisa antes explicados, dos 219 estudos encontrados, apenas 8 foram selecionados. No entanto, foi possível perceber que dos 219 estudos encontrados, a maioria deles se debruçam sobre crenças e identidade de professor de línguas em formação inicial e continuada, apesar de observarmos um leve pressionamento sobre as questões de crenças e emoções. Esses resultados corroboram lacuna identificada por Barcelos (2013) que as há mais pesquisas que enfoquem as questões identitárias na formação dos professores. Ainda, nota-se que o componente emocional permanece sendo pesquisado em separado, de maneira independente de construtos cognitivos, identitários e de crenças (ARAGÃO; 2011; NORTON, 2013; PAVLENKO, 2013; BARCELOS, 2013).

Os resultados da metassíntese qualitativa confirmam, como identificado por Barcelos (2013), que a maior lacuna é que nenhum trabalho empírico envolveu os três conceitos como parte de um mesmo estudo. Os resultados sugerem a necessidade de publicação de trabalhos, que possam estar sendo desenvolvidos sobre a temática pesquisada nessa metassíntese, em revistas na base do Scielo com webqualis A1 a B3. Entretanto, a identificação desses possíveis trabalhos foge do escopo deste artigo. Esse resultado também apresenta a limitação da nossa metassíntese que não investigou outras bases de dados e outros meios de publicação de resultados de pesquisas. 


\title{
QUALITATIVE METASYNTHESIS ON BELIEFS, EMOTIONS AND IDENTITY STUDIES (2009-2014)
}

\begin{abstract}
We present in this study a qualitative metasynthesis of research involving emotions, beliefs and identity in foreign language learning and teaching, published in Brazil between 2009 and 2015. We used the SciELO database as a source of journals with relevant WebQualis A1 to B3 in Liberal Arts/ Linguistics area. We aim at observing the research trends and identify possible gaps in the literature that may need further research. Our results indicate that most of the studies focus on beliefs and language teacher identity. We have identified a small connection on the issues of beliefs and emotions, which indicates a need to have more studies published with relevant WebQualis. We suggest the need for studies that relate identities-emotions-beliefs in foreign language learning and teaching, since this qualitative metasynthesis has not found any work involving the three concepts as part of the same study.
\end{abstract}

KEYWORDS: Beliefs;Emotion; Identity.

\section{REFERÊNCIAS}

ARAGÃO, R. C. Cognição, Emoção e Reflexão na Sala de Aula: por uma abordagem sistêmica do ensino/aprendizagem de inglês. Revista Brasileira de Linguística Aplicada (Impresso), v. 5, 2005 p. $101-122$. CLAFPL, 2010.

Reflexão, linguagem e emoção na pesquisa sobre crenças. Caderno de Resumos III

Emoção no ensino/aprendizagem de línguas. In: MASTRELLADEANDRADE, M.R. (Org.) Afetividade e Emoções no Ensino/Aprendiragem de Linguas: Múltiplos Olhares. Campinas: Pontes Editores, 2011, p.163-189.

Observar, narrar e significar a experiência da aprendizagem. In: MICCOLI, L.S. Pesquisa Experiencial em Contextos de Aprendizagem: Uma abordagem em evolução. Campinas, SP: Pontes Editores, p. 79-99, 2014.

ARNOLD, J.; BROWN, H. D. A map of the terrain. In: ARNOLD, J. (Ed.) Affect in language learning. Cambridge: Cambridge University Press, 1999, p.1-24.

BARCELOS, A.M..F. Desvelando a relação entre crenças sobre ensino e aprendizagem de línguas, emoções e identidades. In: GERHARDT, A.F.L.M; AMORIM, M.A.; CARVALHO, A.M. (Orgs.). Linguística Aplicada e ensino: Língua e Literatura. Campinas: Pontes, 2013, p.153-186.

- Crenças sobre ensino e aprendizagem de línguas: reflexões de uma década de pesquisas no Brasil. In. ALVAREZ, M.L.O.;SILVA, K.A. (orgs.). Linguística Aplicada: múltiplos olhares. Brasília, DF: UnB/Finatec; Campinas, SP: Pontes Editores, 2007.

; COELHO, H.S.H (orgs.) Emoções, reflexões e (trans)form(ações) de alunos, professores 
e formadores de professores de línguas. Campinas: Pontes Editores, 2010.

. Lugares (im)possíveis de se aprender inglês no Brasil: crenças sobre aprendizagem de inglês em uma narrativa. In: LIMA, Diógenes Cândido de. (Org.) Inglês em escolas públicas não funciona? Uma questão, múltiplos olhares. São Paulo: Parábola, 2011, p. 147-158.

BATTISTELA, T. R; LIMA, M. S. A correção em língua estrangeira a partir de uma perspectiva sociocultural e as crenças de professores sobre o assunto. RBLA, Belo Horizonte, v. 15, n.1, p.281302, 2015.

BEDRAN, P. F.; SALOMÃO, A. C. B. Interação de crenças em contexto colaborativo virtual de aprendizagem de línguas. RBLA, Belo Horizonte, v.13, n.3, 2013, p. 789-814.

BENSON, P.; NUNAN, D. (Ed.) Learner's stories: Differences and diversity in language learning. Cambridge: Cambridge University Press, 2004

BOHN, H.I. Maneiras inovadoras de ensinar e aprender: a necessidade de des(re)construção de conceitos. In: Wilson J. Leffa. (Org.). O professor de língua estrangeiras: construindo a profissão. 2da ed.Pelotas, RS:EDUCAT, 2006, v., p. 106-123.

BORG, Teacher cognition in language teaching. London: Continuum, 2006

BORDINI, M.; GIMENEZ, T. Estudos sobre Inglês como Lingua Franca no Brasil (2005-2012): Uma metassíntese qualitativa. Revista Signum: Estudos Linguísticos, Londrina, n. 17/1, 2014, p. 10-43.

CARVALHO, V.C.P.S. A aprendizagem de lingua estrangeira sob a ótica de alunos de Letras: crenças e mitos. Dissertação (Mestrado em Estudos Lingüísticos), Faculdade de Letras, UFMG, Belo Horizonte, 2000.

CHAUDRON, C. A descriptive model of discourse in the corrective treatment of learners' errors. Language Learning, v.27, p.29-46, 1977.

CELANI, M.A.A. (Org.). Professores e formadores em mudança: relato de um processo de reflexão e transformação da prática docente. Campinas, SP: Mercado de letras, 2002

. Perguntas ainda sem resposta na formação de professores de línguas. In: GI-

MENEZ, T.; MONTEIRO, M.C.G. (orgs.). Formação de professores de línguas na América latina e transformação social. Campinas, SP. Pontes Editores, 2010.

COELHO, H.S. Somos capazes de mudar nossa trajetória: experiências e emoções de professoras na educação continuada. In: MICCOLI, L.S. Pesquisa Experiencial em Contextos de Aprendizagem: Uma abordagem em evolução. Campinas, SP: Pontes Editores, p. 267-292, 2014.

CRANDALL, J. J. El aprendizaje cooperativo de idiomas y los factores afectivos. In: ARNOLD, J. (Ed.). La dimensión afectiva en el aprendizaje de idiomas. Trad. Alejandro Valero. Madrid: CUP, 2000. p. 243-260. 
GALLARDO, B. C. Comunicação transnacional mediada por computador: uma análise discursiva das identidades de futuros professores de inglês no Facebook. RBLA, Belo Horizonte, v. 14, n.3, 2014, p. 553-580.

GIMENEZ, Telma. Narrativa. 14: Permanências e rupturas no ensino de inglês em contexto brasileiro. In.: LIMA, Diógenes Cândido de (Org.). Inglês em escolas públicas não funciona? Uma questão, múltiplos olhares. São Paulo: Parábola Editorial, 2011.

GIMENEZ, T. et al. Crenças de licenciados em letras sobre o ensino de inglês. In.: LEFFA, V.J. (Comp.) TELA. (Textos em Linguística Aplicada) [CD-ROM]. Pelotas: Educat, 2000.

HON, F. F. S. Deslocamento identitários de professores no discurso sobre a sua prática de avaliação no processo de educação contiunada. Dissertação. (Mestrado em Linguística Aplicada ao Ensino de Línguas Estrangeiras) - Faculdade de Letras, Universidade Federal de Minas Gerais, Belo Horizonte, 2009.

HOROWITZ, E. Using students' beliefs about language learning and teaching in the foreign language methods course. Foreign Language Annals, v.18, n.4, p.333-340, 1985.

; YOUNG, D. J. Language Anxiety: From theory and research to classroom implications. Englewood Cliffs, NJ: Prentice Hall, 1991.

IMAI, Y. Emotions in SLA: New insights from collaborative learning for an EFL classroom. The Modern Language Journal, 94(2), p.278-292, 2010.

JAMES-WILSON. The influence of ethnocultural identity on emotions and teaching. Annual Meeting of the American Educational Research Association. New Orleans, 2001.

MALATÉR, L. S. de O. Discurso de uma futura professora sobre sua identidade profissional. Revista Brasileira de Linguística Aplicada, v. 8, n. 2, p. 445-464, 2008.

MASTRELLA-DE-ANDRADE, M. R. Falar, fazer, sentir, vir a ser: Ansiedade e identidade no processo de aprendizagem de LE. In: MASTRELLA-DE-ANDRADE, M. R.. (Org.). Afetividade e emoções no ensino/aprendizagem de línguas: Múltiplos olhares. Campinas: Pontes Editores, 2011, v. 18, p. 17-48.

MICCOLI, L. Ensino e aprendizagem de inglês: experiências, desafios e possibilidades. Campinas: Pontes Editores, 2010.

MOREIRA; MONTEIRO. O uso de instrumentos e procedimentos de pesquisa sobre crenças: promovendo formação reflexiva. Trab. Ling. Aplic., Campinas, 49 (1): 205-221, 2010.

NEVES, M. de S. O processo identificatório na prática de assistência ao aluno com dificuldades de inglês como LE no curso de Letras. RBLA, Belo Horizonte, v.9, n. 2, 2009, p. 563-582.

NORTON, B. Identity and Language Learning: extending the conversation. London: Longman, 2013. 
PACKER, A.L., et al., orgs. SciELO - 15 Anos de Acesso Aberto: um estudo analítico sobre Acesso Aberto e comunicação científica. Paris: UNESCO, 2014, 188 p. ISBN 978-92-3701237-6. Available from: http://dx.doi.org/10.7476/9789237012376.

PAIVA, Geraldo J. Identidade Psicossocial e Pessoal como Questão Contemporânea. Porto Alegre: Psico PUCRS, v.38, n.1, p.77-84, jan./ abr. 2007.

PAVLENKO, A. The affective turn in SLA: From 'affective factors' to 'language

desire' and 'commodification of affect'. In D. Gabryś-Barker \& J. Bielska (Orgs.), The affective dimension in second language acquisition. Bristol: Multilingual Matters, 2013, p. 930 .

PONZIO, A. Procurando uma palavra outra. São Carlos: Pedro e João Editores, 2010.

PRICE, M. L. The subjective experience of foreign language anxiety: interviews with highanxious students. In: HORWITZ, E. K.; YOUNG, D. J. (Ed.). Language Anxiety: From Theory and Research to Classroom Implications. Englewood Cliffs, NJ: Prentice Hall, 1991, p. 101108.

REIS, V. da S.; SILVA, L. de C.; TORRES, A. M. M. S. Teorizando a prática ou praticando a teoria? Os deslocamentos identitários de duas professoras de inglês em grupo de pesquisa-ação. Trab. Ling. Aplic., Campinas, 50 (1), 2011, p. 55-74.

REZENDE, T. C. de. Autoestudo sobre as emocões de uma professora de inglês em uma escola pública. 2014. 128f. Dissertação (Mestrado em Letras) - Universidade Federal de Viçosa, Minas Gerais, 2014.

RICHARDS, J. Practice Teaching: reflective approach. Cambridge, 2011.

SANDELOWSKI M , BARROSO. J. Toward a metasynthesis of qualitative findings on motherhood in HIV-positive women. Research Nursing Health. 2003(b) 26:153-170.

SARNIGHAUSEN, V. C. R. Revisão sistemática e metassíntese: medições de gases de efeito estufa (GEE) emitidos pela pecuária bovina brasileira. 2011. Tese (Doutorado em Física do Ambiente Agrícola) - Escola Superior de Agricultura Luiz de Queiroz, Piracicaba.

SERRANI-INFANTE, S. M. Ressonâncias discursivas y cortesiaem prácticas de lecto-escritura. D.E.L.T.A., v. 17, n. 1, p. 31-58, 2001.

SCOVEL, T. The effect of affect on foreign language learning: A review of the anxiety research. In: HORWITZ, E. K.; YOUNG, D. J. Language Anxiety: From Theory and Research to Classroom Implications. Englewood Cliffs, NJ: Prentice Hall, 1991, p 15-23.

SHAVELSON, R. J., \& STERN, P. Research on teachers' pedagogical thoughts, judgements, decisions, and behaviour. Review of Educational Research, 51, 455-498, 1981. 
STELLA, P. R. ; CRUZ, D. A. C. O. da. Formação de professores de inglês pré-serviço em Alagoas: uma reflexão sobre identidades. Revista Brasileira de Linguistica Aplicada, v 14, n. 1, 2014, p. 141-159.

REIS, V. da S.; SILVA, L. de C.; TORRES, A. M. M. S. Teorizando a prática ou praticando a teoria? Os deslocamentos identitários de duas professoras de inglês em um grupo de pesquisa-ação. Trabalhos de Linguistica Aplicada, Campinas, 50(1): 55-74, 2011

SOUZA, R. A. Telecolaboração na aprendizagem de línguas estrangeiras: um estudo sobre o regime de tandem. In: FIGUEIREDO, F. J. Q. A aprendiragem colaborativa de linguas. Goiânia: Editora UFG, 2006. p. 255-276.

SHULMAN, L. S. . Those who understand: Knowledge growth in teaching. Educational Researcher, 15(2), 1986, p.4-14.

TELLES, J. A reflexão e identidade profissional do professor de LE: Que histórias contam os futuros professores? Revista Brasileira de Linguística Aplicada, v. 4, n. 2, 2004, p. 57-83.

; J. A.; VASSALLO, M. L. Foreign language learning in-tandem: Teletandem as an alternative proposal in CALLT. The ESPecialist, v. 27, n. 2, p. 189-212, 2006.

VYGOTSKY, L. S. Mind in society: the development of higher psychological processes. Cambridge, MA: Havard University Press, 1978.

Thought and Language. Cambridge: MIT Press, 1986.

WEBSTER, L.; MERTOVA, P. Using Narrative Inquiry as a Research Method. London; New York: Routledge, 2007.

ZEMBYLAS, M. Caring for teaching emotion: reflections on teacher self-development. In: Studies in Philosophy and Education. Netherlands: 2003, p.103-125.

. The emotional characteristics of teaching. Teaching and Teacher Education, v. 20, p. 185-201, 2004.

."Discursive practices, genealogies, and emotional rules: A poststructuralist view on emotion and identity in teaching". Teaching and Teacher Education (21): 935-948, 2005.

ZOLIN-VESZ, Crenças sobre o ensino-aprendizagem de espanhol em uma escola pública. RBLA, Belo Horizonte, v. 13, n.3, p. 815-828, 2013.

Recebido em: 05/07/2017.

Aprovado em: 20/12/2017. 